\title{
KAJIAN KEKUATAN DAN KELEMAHAN STRATEGI PEMASARAN GENTENG BETON DI BANDAR LAMPUNG (STUDI KASUS MENEJEMEN STRATEGI)
}

Oleh :

Dr. Sophan Syaiful, M.M.

Jurusan Manajemen, Universitas Mitra Indonesia e-Mail : rachmatandfamily@gmail.com

\begin{abstract}
ABSTRAK
CV. Gunung Rajabasa merupakan Perusahaan Industri yang bergerak di bidang penyediaan bahan bangunan yang berada di bandar lampung.

Permasalahan dalam penelitian ini adalah apakah strategi pemasaran yang diterapkan CV. Gunung Rajabasa belum tepat, sedangkan data yang digunakan berasal dari CV, Gunung Rajabasa, dinas tata kota Bandar Lampung, Perumnas Bandar Lampung dan perusahaan pesaing

Tujuan dan kegunaan penelitian untuk mengetahui dan menentukan strategi pemasaran yang tepat dalam menghadapi pesaing.

Hal ini di kaitkan dengan volume penjualan menunjukan bahwa strategi pemasaran yang dilakukan CV. Gunung Rajabasa selama lini belum tepat.
\end{abstract}

Kata Kunci: Kekuatan, Kelemahan, Stretegi Pemasaran. 


\section{PENDAHULUAN}

\section{A. Latar Belakang Masalah}

Penggunaan genteng beton Perusahaan CV. GUNUNG RAJABASA sebagai atap bangunan mengalami persaingan dengan perusahaan genteng biasa dan asbes yang terus berkembang.

Walaupun demikian genteng beton masih banyak peminatnya, karena memiliki keungulan yaitu antara lain :

1. Tahan api dan tidak mudah bocor

2. Nyaman karena meredam panas

3. Beratnya sedang

Kesempatan atau peluang pemasaran genteng beton dapat dari jumlah bangunan yang meningkat pada table 1 , dibawah ini :

\begin{tabular}{|l|l|l|l|l|}
\hline $\begin{array}{l}\text { Tah } \\
\text { un }\end{array}$ & $\begin{array}{l}\text { Rum } \\
\text { ah }\end{array}$ & $\begin{array}{l}\text { Pertoko } \\
\text { an }\end{array}$ & $\begin{array}{l}\text { Guda } \\
\text { ng }\end{array}$ & $\begin{array}{l}\text { Perkanto } \\
\text { ran }\end{array}$ \\
\hline 1996 & 2665 & 103 & 56 & 112 \\
1997 & 2689 & 107 & 60 & 115 \\
1998 & 2724 & 111 & 61 & 116 \\
1999 & 2735 & 116 & 63 & 120 \\
2000 & 2811 & 126 & 70 & 121 \\
2001 & 3026 & 143 & 74 & 123 \\
\hline
\end{tabular}

Sumber : Dinas Tata Bandar Lampung, Perumnas Bandarlampung 2002

Perusahaan lain yang memproduksi sejenis merupakan saingan bagi Perusahaan CV. Gunung Rajabasa. Pada tahun 2001 CV. Gunung Rajabasa menduduki nilai sebesar $20,26 \%$, untuk PT. Sinar laut menguasai sebesar $36,40 \%$

Tabel 2, Perusahaan genteng beton di Bandart Lampung Pangsa pasarnya pada tatun 1997$2001(\%)$.

\begin{tabular}{|c|l|c|c|c|c|c|}
\hline \multirow{2}{*}{ No } & \multirow{2}{*}{$\begin{array}{l}\text { Nama } \\
\text { Perusahaan }\end{array}$} & \multicolumn{5}{|c|}{ Pangsa Pasar Dalam (\%) } \\
\cline { 3 - 7 } & & 1997 & 1998 & 1999 & 2000 & 2001 \\
\hline 1. & $\begin{array}{l}\text { PT. SINAR } \\
\text { LAUT }\end{array}$ & 39,58 & 35,65 & 35,98 & 36,10 & 36,40 \\
\hline 2. & $\begin{array}{l}\text { CV. } \\
\text { GUNUNG } \\
\text { RAJABASA }\end{array}$ & 25,98 & 25,72 & 25,85 & 20,66 & 20,26 \\
\hline 3. & $\begin{array}{l}\text { CV. SINAR } \\
\text { INDAH }\end{array}$ & 25,98 & 25,72 & 25,85 & 20,66 & 20,26 \\
\hline 4. & JAYA & 10,53 & 10,67 & 10,60 & 12,50 & 12,60 \\
\hline
\end{tabular}

\begin{tabular}{|c|l|l|l|l|l|l|}
\hline & YENNY & & & & & \\
\hline 5. & $\begin{array}{l}\text { CV. SINAR } \\
\text { DUNIA }\end{array}$ & 8,90 & 8,93 & 8,98 & 8,95 & 8,92 \\
\hline 6. & $\begin{array}{l}\text { CV. } \\
\text { PELANGI }\end{array}$ & 8,05 & 8,14 & 8,10 & 8,22 & 8,25 \\
\hline & Lain-lain & 5,33 & 5,45 & 5,40 & 6,89 & 6,91 \\
\hline
\end{tabular}

Tujuan strategi pemasaran adalah melalui kebijakan distribusi, produksi, promosi dan harga, untuk meningkatkan penjualan yang optimal serta menambah sekmen pasar.

\section{A. TUJUAN DALAM PENELITIAN}

1. Mengetahui strategi pemasara

2. Pemikiran dalam melaksanakan strategi pemasaran

Pemasaran melaksanakan program dangan baik sehingga laba dan target penjualan yang telah direncanakan dapat tercapai.

Pemasaran sesuai dengan tujuan dan sasaran perusahaan, strategi pemasaran melihat dengan baik faktor-faktor yang mendasr antara lain :

1. Ukuran besar dan posisi persainga perusahan

2. Sumber, tujuan, dan kebijaksanaan

3. Aneka strategi pemasaran

4. Perilaku pembeli dalam pasar yang di targetkan

5. Tahap daur usia produksi

Dalam kegiatan pemasara bagi Perusahaan adalah mengkobinasikan $\mathrm{dn}$ mengkoordinirberbagai variable pemasaran, agar dapat melaksanakan program pemasaran dengan baik sehinga laba dan target penjualan yang direncanakan dapat tercapai.

* Menurut Freddy Ranfuli (1997 : 118) Pengertian Pemasaran adalah suatu kegiatan yang dipengaruhu oleh factor sosial, budaya, politik dan manajerial.

* Menurut Philip Kothle (1997 : 8)

Pemasaran adalah sosial dan manajerial di mana indifidu dan kelompok mendapat kebutuhan dan keinginan dengan menciptakan, menawarkan, dan bertukar sesuatu yang bernilai satu sama lain. 
* Menurut Basu Swastha dan Irwan (1985: 12)

Sistem pemasaran adalah kumpulan lembaga-lembaga yang melakukan tugas pemasaran, barang, jasa, ide, orang dan faktor - faktor lingkungan yang saling mempengaruhi hubungan pemasaran.

* Menurut Philip Khotler (1990 : 401)

Strategi pemasaran adalah pendekan pokok yang digunakan dalam unit bisnis dalam mencapai sasaran yang ditetapkan, di dalam tercantum keputusan pokok mengenai target pasar, penepatan produk di pasar, bagan pemasaran dan tingat pemasaran yang diperlukan.

\section{B. METODE PENELITIAN}

1. Jenis penelitian Dengan cara terjun langsung ke Perusahaan dan karyawan

2. Objek Penelitian

Strategi pemasaran yang di lakukan Perusahaan genteng beton CV. Gunung Rajabasa

3. Teknik pengumpulan data

Dengan cara : Wawancara, observasi, studi pustaka dan dokumentasi

\section{Strategi Produksi}

Merupakan barang atau jasa yang di tawarkan perusahaan kepada pasar. Produksi yang merupakan barang atau fisik dapat digolongkan menjadi dua yaitu:

- Barang konsumen

Yaitu barang-barang yang dibeli untuk dikonsumsi. Barang konsumen dibedakan menjadi tiga golongan dari pengonsumsi yaitu :

- $\quad$ Barang Konvenien (Convenien Goods) Barang yang mudah dipakai, membeli dapat disembarang tempat dan pada setiap waktu.

- $\quad$ Barang Shopping (Shopping Goods) Barang dalam pembelianya harus mencari dahulu dan dalam membelinya harus dipertimbangkan massak-masak.

- $\quad$ Barang Spesial (Special Gooods)
Barang yang mempunyai ciri khas dan hanya dapat dibeli pada tempat tertentu saja. Pembeli yang ingin memperoleh barang harus mengeluarkan pengorbanan yang istimewa.

\section{b. Barang Industri}

Barang yang dibeli untuk diproses lagi atau untuk kepentingan dalam industri. Lembaga atau organisasi, termasuk organisasi yang tidak mengutamakan laba.

Pada dasarnya produksi merupakan kombinasi barang dan jasa. Adapun kombinasi barang dan jasa yang dapat perhatian terdiri dari empat macam, yaitu :
1. $\quad$ Produk Line and Quality
2. Merek (Brand)
3. Pembungkusan (Packaging)
4. Pelayanan (Service)

\section{Strategi Harga}

Merupakan penetapan yang cukup rumit dan cukup sulit bagi perusahaan. Perusahaan harus dapat menetapkan harga yang paling tepat dalam arti dapat memberikan keuntungan yang paling baik. Apabila perusahaan menetapkan harga yang salah, maka akan menimbulkan kesulitan dalam perusahaan bahkan dapat menyebabkan kegagalan bagi perusahaan.

Adapun definisi arti harga barang dari beberapa ahli, yaitu :

\section{Menurut Alex S. Nitisemito (1993 : 55)}

1. Harga adalah nilai suatu barang/jasa yang diukur dengan sejumlah uang berdasarkan nilai tersebut seseorang atau perusahaan bersedia melepaskan barang/jasa yang dimiliki kepada pihak lain.

2. Menurut William J. Stanton (Basu Swastha dan Irwan, $1985: 341$ )

Harga adalah sejumlah uang (ditambah beberapa produk kemungkinan) yang dibutuhkan untuk mendapatkan sejumlah kombinasi dari produk dan pelayanannya.

Dalam definisi-definisi diatas dapat diambil kesimpulan, bahwa harga merupakan cara 
untuk mengukur suatu barang atau jasa yang dinilai dengan uang guna mendapatkannya :

Tujuan penepatan harga adalah sebagai berikut :
a. Meningkatkan penjualan
b. Meningkatkan dan mempertahankan Pangsaa Pasar
c. Menciptakan kestabilan harga
d. Mencapai target pengambilan investasi
e. Mencapai laba maksimum, dan sebagainya

Menurut Basu Swastha dan Irawan (1985 : 342), Faktor-faktor yang mempengaruhi tingkat harga adalah :
a. Keadaan Prekonomian
b. Permintaan dan Penawaran
c. Elastistas Permintaan
d. Struktur Pasar akan persaingan
e. Biaya
f. Tujuan Perusahaan
g. Pengawasan pemerintah

\section{Srategi Promosi}

Menurut Basu Swastha dan Irwan (1985 : 349) Promosi adalah usaha perusahaan untuk memberitahu, membujuk atau meningkatkan konsumen tentang perusahaan, produk atau idenya agar tujuan perusahaan dapat tercapai.

Kegiatan-kegiatan dalam bentuk promosi yaitu :

1. Perikalanan atau advertensi, yaitu usaha promosi yang dilakukan oleh perusahaan untuk memberitahukan, meningkatkan dan membujuk pengonsumsi mengenai produk perusahaan, atau suatu ide melalui seperti surat kabar, poster, pemutaran slide film, spanduk, siaran radio dan lainlain.

2. Penjualan Pribadi, yaitu promosi yang dilakukan penjualan yang mengadakan komnikasi secara individu atau berhadapan langsug dengan pengonsumsi atau pembeli.

\section{Strategi Saluran Distribusi Menurut Alex S. Nitisemito (199 :285) :}

Saluran distiribusi yaitu saluran yang dipakai oleh produsen untuk menyalurkan barang atau jasa dari produsen ke konsumen atau pemakai industry.

Faktor-faktor yang mempengaruhi dalam memilih saluran disribusi yang akan dipergunakan adalah :

1. Pertimbangan Pasar

2. Pertimbangan barang

3. Pertimbangan Perusahaan

4. Pertimbangan perantara

C. Lingkungan Pasar

Lingkungan pemasaran adalah suatu totalitas kekutan dan keadaan yang mempengaruhi pemasaran produksian terentu. Lingkungan pasar meliputi:

1. Lingkungan Organisasi

2. Lingkungan pasar

3. Lingkungan Makro

D. Srategi Pemasaran

Srategi pemasaran adalah pendekatan pokok yang digunakan unit bisnis dalam mencapai sasaran yang ditetapkan , didalamnya tercantum keputusan pokok megenai taget pasar, penempatan produk dipasar, bauran pemasaran dan tingkat biaya pemasaran yang diperlukan.

Daur kehidupan produksian terbagi dalam empat tahap :
1. Tahap Perkenalan
2. Tahap Pertumbuhan
3. Tahap Kedewasaan
4. Tahap Kemunduran

\section{E. Strategi Persaingan}

Strategi persaingan ditunjukan dengan dilakukanya penelitian khusus, bahwa perusahaan akan mengambil keuntungan suatu gambaran yang baik pada pasar-pasar yang ada. Oleh karena itu dilihat dari tiga aspek dalam strategi persaingan yaitu:

1. Dengan cara membedakan generic, product form, dan enterprise competition.

2. Mencoba menerapkan prinsip-prinsip strategi terhadap enterprise competition. 3. Memilih straregi persainga yang bersedia untuk menghadapi persaingan yang lebih kecil, perusahaan yang berpengaruh, dan perusaan setingkat (H. Surachman Sumawihardji, 1985 :84) 
1. Sifat dan type Persaingan

\section{Persaingan}

memberikan informasi secara aktif dalam berbagai hal tantang sumber-sumber ; Kekuatan, usaha, kesetiaan dan sebagainya. adalah :

Sedangkan type dari persaingan

a. Competition : yaitu membuat produksia sejenis

b. Rival: membuat produksian berbeda tetapi bersaing dalam pasar yang sama.

c. Opponents : yang merintangi operasi perusahaan.

d. Enemies : yang meyakini atau menghancurkan perusahaan lain.

2. Identifikasi Pemilihan Strategi Persaingan

Perlu diketahui terlebih dahulu tentang pemilihan strategi yang utama bagi setiap Perusahaan pada saat tertentu, karena hal itu akan berbeda satu dengan yang lainnya.

Strategi tesebut dapat dibedakan menjadi empat keadaan yaitu : 1. Strategi untuk perusahaan lebih kecil 2. Srategi untuk perusahaan yang dominan 3 . Srategi perusahaan yang mempunyai ukuran yang sama dengan perusahaan lain.

4. Srategi perusahaan kecil yang berusaha menjadi lebih besar dalam suatu industi dengan persaingan secara monopolistis.

\section{GAMBARAN UMUM PERUSAHAAN}

\section{A. Sejarah Singkat Perusahaan}

Perusahaan CV. Rajabasa di dirikan pada tahun 1980 dengan akte Pendirian No. 37 Juni 1980 dihadapan Notaris Imam Ma'ruf, S.H., Pabrik Perusahaan terletak di Jl. Kapten Abdul Hak, Way Kandis, Rajabasa Bandar Lampung, areal seluas $2500 \mathrm{~m}^{2}$, berdasarkan izizn walikotamadya dengan SK No. 642/TBU/1980 dan SK Menteri Perindustrian No. 26/2682.IK.2105/341-11/80, tentang pemberian izin usaha tetap.

\section{Sruktur Organisasi Perusahaan}

Adapun struktur organisasi CV. Gunung

Rajabasa yang terdiri dari :

1. Pemimpin/ Direktur

2. Bagian Administrasi/peruangan

3. Bagian Produksi

4. Bagian Pemasaran

5. Bagian Personlia

6. Bagian Pembelian

7. Bagian Pengelolaan

8. Bagian Pergudangan

\section{ANALISIS DATA DAN PEMBAHASAN}

\section{A. Analisis SWOT Secara Kualitas dan Kuantitatif}

Berdasarkan hasil perhitungan pada hasil pengisian formulir analisis SWOT lampiran 4 diperoleh dengan hasil pendekatan pada tabel dibawah ini Tabel 6.

Hasil ringkasan pengisian formulir SWOT

\begin{tabular}{|l|l|l|l|}
\hline \multirow{2}{*}{ No. } & Jenis Penilaian & \multicolumn{2}{|l|}{ Perusahaan } \\
\cline { 3 - 4 } & & $\begin{array}{l}\text { CV. } \\
\text { Gunung } \\
\text { Rajabasa }\end{array}$ & $\begin{array}{c}\text { PT. } \\
\text { Sinar } \\
\text { Laut }\end{array}$ \\
\hline 1. & Harga & 895 & 900 \\
2. & Produksian & 1100 & 1100 \\
3. & Promosi & 1125 & 1500 \\
4. & Tempat & 800 & 800 \\
5. & Pelayana n & 1000 & 1200 \\
6. & Teknologi & 900 & 900 \\
7. & $\begin{array}{l}\text { Sosial Budaya } \\
\text { dan Geografi }\end{array}$ & 600 & 500 \\
8. & Pesaing & 400 & 400 \\
\hline
\end{tabular}


1. Strategi Penetapan harga

CV. Gunung Rajabasa mempunyai nilai 895, nilai ini lebih rendah dibandinlgkan dengan pesaingnya PT. Sinar Laut yang memperoleh nilai sebesar 900 .

\section{Strategi Produksin}

Dari hasil perhitungan analisis SWOT diperoleh hasil bahwa CV. Gunung Rajabasa m,empunyai nilai yang sama dengan PT. Sinar Laut yaitu seberar 1100 hal nilai hal ini berarti kedua perusahaan menekan kan pada kualitas produksian dan persedian barang yang cukup.

\section{Strategi Promosi}

Promosi yang dilakukan PT. Sinar Laut lebih gencar dibandingkan dengan $\mathrm{CV}$. Gunung Rajabasa selain itu kegiatan promosi yang dilakukan PT. Sinar Laut melalui papan reklame, surat kabar, brosur dan mengikuti pameran-pameran serta penjualan pribadi. Sedangkaln untuk CV.Gunung Rajabasa kegiatan promosi yang dilakukannya yaitu hanya melalui selembaran/brosur dan mengikuti pameran-pameran dan penjualan pribadi.

\section{Strategi Tempat/ lokasi}

Untuk lokasi baik CV. Gunung RAJABASA dan PT. Sinar Laut terletak di jalan raya dan dapat dengan mudah didatangi konsumen

\section{Strategi Pelayanan}

Dari segi pelayanan CV. Gunung Rajabasa melayani dengan jangka waktu 6-12 bulan sedangkan pengantaran barang ketempat konsumen dilakukan oleh kedua perusahaan tetapi pada CV. Guinung Rajabasa batas pembelian minimum yang di antar ketempat jumlahnya lebih besar di bandingkan dengan perusahaan pesaing.

\section{Strate Pemanfaatan Teknologi}

PT. Sinar Laut dan CV. Gunung Rajabasa sama-sama telah memanfaatkan teknologi yang ada untuk meingkatkan produksi dan volume penjualan sehingga teknologi akan menjadi kesempatan perusahaan untuk memperbsar pangsa pasar Perusahaan dari Perusahaan Pesaing yang ada.

\section{Strategi Sosial Budaya dan Geografi}

Faktor sosial Budaya berpengaru positif terhadap perkembangan genteng beton sedangkan foktor geografi juga berpengaru positif, berarti kedua foktor tersebut mendukung terhadap perkembangan genteng beton

\section{Strategi Pesaing}

Untuk Pesaing CV. Gunung Rajabasa memiliki nilai sama dengan PT. Sinat Laut sebesar 400, hal ini berarti meningkatnya jumlah pesaing merupakan ancaman bagi perusahaan lain.

\section{KESIMPULAN DAN SARAN}

\section{Kesimpulan}

a. CV.Gunung Rajabasa pada pengisian Foemulir analisa SWOT memperoleh nilai sebesar 6820, sedangkan PT. Sinar Laut memperoleh nilai SWOT seberar 7300 penilaian ini menunjukkan bahwa strategi pemasaran yang diterapkan oleh CV. Gunung Rajabas selama ini belum tepat.

b. Kekuatan yang dimiliki oleh CV. Gunung Rajabasa meliputi kualitas produksian dapat bersaing, tempat yang cukup strategis dan CV. Gunung Rajabasa melakukan pendistribusian secara langsung pada konsumen.

c. Kelemahan CV. Gunung Rajabasa terletak pada pada penerapan harga yang relatif tinggi, tingkat pelayanan yang rendah dan kegiatan promosi yang kurang gencar dilakukan perusahaan . 


\section{Saran}

a. Dalam menghadapi peraing hendaknya penetapank harga harus disesuaikan dengan harga pesaing

b. Perusahaan sebaiknya melakukan Promosi secara lebih gencar lagi denkgank memper banyak pengunaan priklanan dan tenaga penjualan.

c. Perusahaan sebaiknya memberikan pelayanan yang lebih baik dari pada perusahaan pesaing.

\section{Daftar Pustaka}

Assauri, Sofyan 1992. Manajemen Pemasaran, Dasar Konsep dan Strategi, penerbit CV Rajawali, Jakarta

Kotler, Philip 1990. Manajemen Pemasaran. Perencanaan dan Pengembangan jilid II edisi kelima, Penerbit Erlangga, Jakarta
Nazir, Moh 1998. Metode Penilitian. Cetakan Ketiga. Penerbit Ghalia Indonesia, Jakarta

Swastha, Basu 1984. Azas-azas Marketing edisi ketiga. Penerbit Liberty, Yogyakarta

Rangkuti, Freddy 1997. Analisis SWOT Teknik Membedah Kasus Bisnis. Penerbit PT. Gramedia Pustaka Utama, Jakarta

Stanton, William 1994. Prinsip Pemasaran. Penerbit Erlangga, Jakarta

Supranto J 1989. Statistik Teori dan Aplikasi II. Pene Erlangga. Jakarta

Sudmawihardja, H Surachman dkk Intisari Manajemen Pemasaran. Penerbit CV Remaja Karya, Bandung

Winardi 1986. Azas-azas Marketing. Penerbit Alumni, Bandung 